\title{
EFFICACY OF MICRONUTRIENT FORTIFIED SUPPLEMENTARY FOODS (READY TO COOK AND READY TO EAT) AND TAKE-HOME RATION (THR) IN CHILDREN WITH MODERATE ACUTE MALNUTRITION (MAM) USING COMMUNITY BASED APPROACH
}

\author{
Pushkala Ramchandran ${ }^{1}$, Nikita Patel ${ }^{1}$, Harini Swaminathan ${ }^{1}$, Alka Jadhav ${ }^{2}$. Priyanka Shinde ${ }^{2}$, \\ Prachi Karnik², D Parthasarathy3, Narendra G Shah ${ }^{3}$ \\ ${ }^{1}$ Centre for Technology Alternatives for Rural Areas, IIT Bombay, India, \\ 2Department of Paediatrics, LTMGH, Sion, Mumbai, India, \\ ${ }^{3}$ Humanities and Social Sciences, IIT Bombay, India.
}

\begin{abstract}
Aim: To compare the efficacy of formulated fortified supplementary foods: ready-to-cook (RTC) and ready-to-eat (RTE) with government take home ration (THR) in children with moderate acute malnutrition (MAM).

Methods and Materials: This randomised controlled trial (RCT) was conducted in Anganwadis of Dharavi, Mumbai, India. The Anganwadis were clustered and assigned under treatment (children received RTC or RTE) and control groups (children who consumed THR). MAM children were divided into two groups, i.e. 6-24 and 25-60 months of age. Of 5,667 children screened, 324 were enrolled. Younger children received $250-300 \mathrm{kcal}$ and $10-12 \mathrm{~g}$ proteins per day and the older children received 450-500 kcal and 12-15 $\mathrm{g}$ proteins per day. Intervention was carried out for 3 months with a follow up of 3 months. Weight, height and Mid Upper Arm Circumference (MUAC) were monitored.
\end{abstract}

Results: In treatment group, weight gain was $0.75 \mathrm{~g} / \mathrm{kg} / \mathrm{d}$ whereas in control group it was $0.52 \mathrm{~g} / \mathrm{kg} / \mathrm{d}$ at the end of 3 months $(p=0.01)$. With micronutrient fortified foods in combination with nutrition counselling, $39.2 \%$ children with MAM recovered.

Conclusion: The weight gain was higher in the treatment group who consumed the micronutrient fortified foods compared to the control group children who consumed THR.

\section{ARTICLE HISTORY}

Received 10 December 2019

Accepted 22 January 2020

\section{KEYWORDS}

Micronutrient fortification, Ready-to-Cook, Ready-toEat, MAM children, Take Home Ration, protein supplementation

\section{Introduction}

One of the leading public health issues in India is malnutrition, with the burden of malnourished children being one of the highest amongst the world. ${ }^{1}$ Over $67 \%$ of deaths in children under 5 years of age has been estimated to have occurred due to the detrimental effects of under-nutrition. ${ }^{2}$ Malnutrition and infections are interlinked with a malnourished child having an increased risk of infection. ${ }^{3}$ Most of the programs addressing malnutrition are aimed at addressing malnutrition in rural pockets of the country. Urban malnutrition, largely unnoticed is on a steady rise, stemming from rapid urbanisation, increasing urban poverty, and inadequate availability of health care of high quality. Specific sections of marginalised communities, such as slum dwellers, not necessarily in the low-income category, record a high rate of malnutrition, mostly due to low standards of living and an improper diet. ${ }^{4}$ In Mumbai, as per the NFHS-IV, prevalence of malnutrition

\section{CONTACT Narendra G Shah}

Email: prof.narendra.shah@gmail.com

Address for Correspondence: Narendra G Shah, CTARA, 2nd Floor Old CSE Building, IIT Powai, Mumbai 400 076, India.

(c)2020 Pediatric Oncall in children below the age of 5 years is $26 \%$. It has been recognised that urban malnutrition is turning into a serious concern, with high under five mortality rates. ${ }^{4}$ Moderate acute malnutrition (MAM) is defined as weight-for-height $\mathrm{z}$-score (WHZ) between -3 and -2 of the World Health Organization (WHO) child growth standards. ${ }^{5}$ Children with MAM are at an increased risk of shifting to severe acute malnutrition (SAM) (WHZ below -3), a life-threatening condition. ${ }^{5}$ Therefore, management of MAM needs attention. One of the common methods to address this issue is providing supplementary foods, majorly fortified blended flours made from low cost, locally sourced ingredients. ${ }^{6}$ Supplementation has emerged as an effective strategy for improving the nutritional status of children. As per a systematic review of 33 randomised controlled trials (RCTs) which involved studies from low and middle-income countries (LMICs), iron supplementation alone decreased anemia (relative risk [RR] 0.51) and reduced iron deficiency (RR 0.24). ${ }^{7}$ Clear policies for integrating micronutrient dense food are necessary to compensate for deficiencies. A comprehensive review of 18 trials from developing countries indicated multiple micronutrient supplementation for children resulting in increasing length (mean difference [MD] 0.13) and weight (MD 0.14). ${ }^{8}$ Preventive zinc supplementation 
showed significant effects in a review of 18 RCTs as mean height in children below 5 years improved by $0.37 \mathrm{~cm}$ and diarrhea reduced by $13 \% .{ }^{9,10}$ Such interventions provide evidence that fortified foods improve the nutritional status of children.

In India, Take Home Ration (THR) made of soya flour/ gram flour as the major ingredient, is provided through the Integrated Child Development Services (ICDS) of the Government of India. However, the recovery rates of children consuming THR is reported to be unsatisfactory, which could be attributed to low nutrient density of the foods. ${ }^{11}$ Some African countries provide RUSF (Ready to Use Supplementary Food) to address MAM condition and the results were encouraging. ${ }^{12,13}$ With a large vegetarian population in India, efforts were made to fortify milk in an earlier study involving children from northern India whereby fortified milk reduced odds for days of severe illnesses by $15 \% .{ }^{14}$ However, consumption of RUSF daily for a long period of time is quite monotonous and results in low compliance. Hence, in the present study, micronutrient fortified nutrient dense foods were developed from locally available traditional ingredients and the distribution was executed following a community-based management approach (CMAM) in association with ICDS. This study was a randomised cluster trial (RCT) in MAM children who were divided into treatment (children received micronutrient fortified foods) and control (children received THR) groups and compared the efficacy of both these interventions.

\section{Methods \& Materials}

\section{Study Design}

This RCT determining efficacy of Micronutrient fortified foods (MFF) with THR in children with MAM was conducted by four partners, Indian Institute of Technology-Bombay (IIT-B), LTMG Hospital, Integrated Child Development Services (ICDS) and Society for Nutrition, Education and Health Action (SNEHA). The duration of the study was 6 months i.e. 3 months of food-product intervention (Figure 1 ) followed by 3 months of follow up. The major objective was to assess the rate of weight gain and recovery rates of children receiving MFF and THR. Second objective was to come out with advisory on "food-products" that can be introduced in governmental supplementary food-program in Anganwadis (preschool).

Figure 1. Flow diagram of intervention

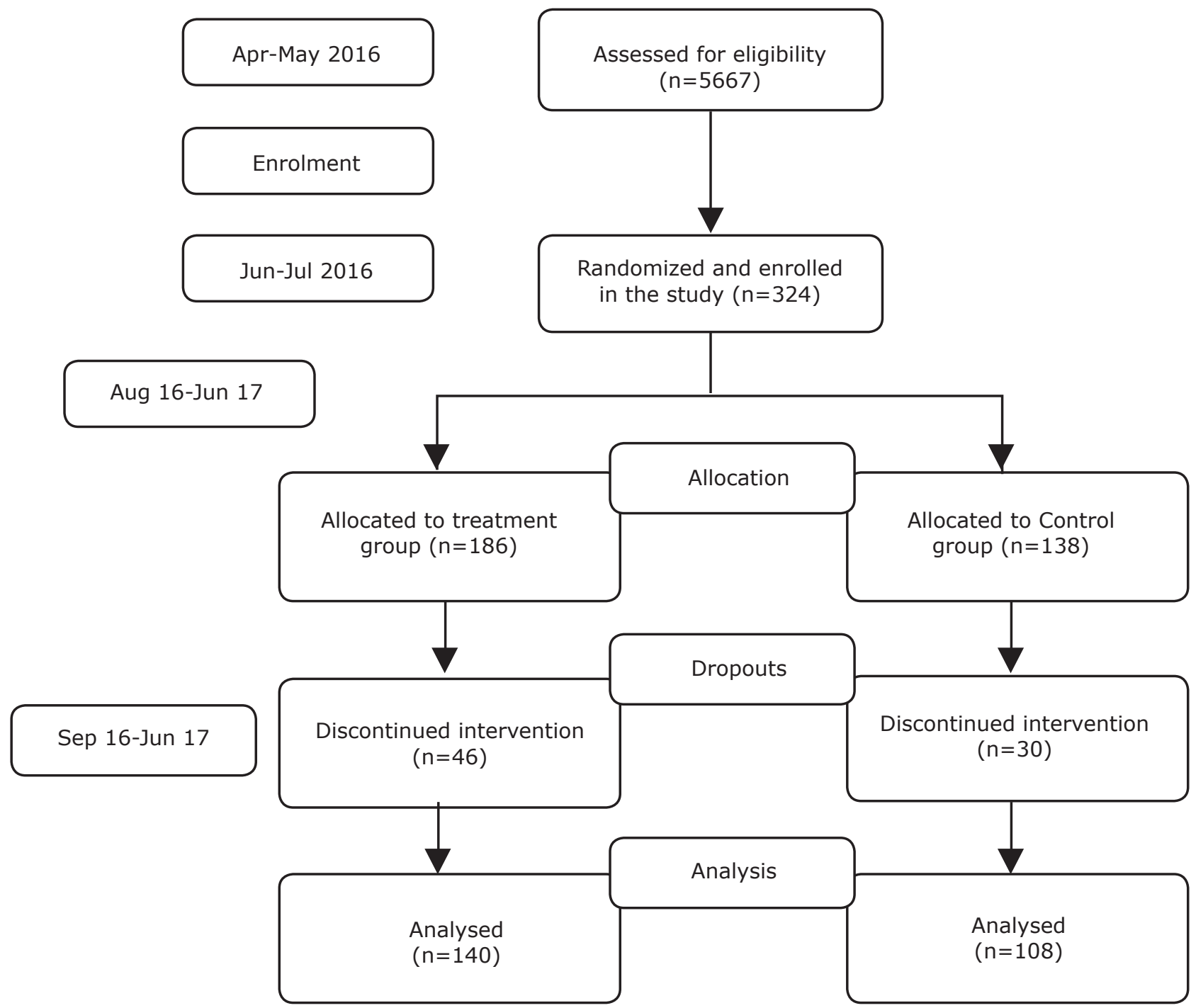




\section{Study location}

The study was carried out in Dharavi, a slum located in Mumbai. There are 300 Anganwadis under ICDS spread across Dharavi. Based on the geographic location, the 300 Anganwadis were grouped into 19 clusters. Each cluster consisted of approximately 12-15 Anganwadis which were then randomized into Treatment $(T)$ and Control (C) clusters using random number generator function of Microsoft Excel 2010. The Anganwadis in the $\mathrm{T}$ and $\mathrm{C}$ clusters were further narrowed to 121 for the study using the same randomization method. To ensure minimum bias in sample selection, randomization was conducted at two levels. Of the total of 121 study Anganwadis, 64 were into Treatment group and 57 in Control group.

\section{Training for anthropometry and food delivery}

Once the Anganwadis for the study were selected, training was conducted for the Anganwadi workers to ensure precision in anthropometric measurements (weight, height and mid-upper arm circumference [MUAC]), using WHO growth charts for identification of MAM children. ${ }^{5}$ Children were defined as MAM when they have $\mathrm{WHZ}$ between -2 and -3 and or MUAC between 115-125 mm, SAM if they have a WHZ <-3 and or MUAC $<115 \mathrm{~mm}$, and normal with a WHZ $>-2$ and or MUAC $>125 \mathrm{~mm}^{5}$

\section{Recruitment of Participants}

Children were screened in all 121 Anganwadis and those identified as MAM were considered for enrolment. Pediatrician examined the children for their health status and to validate MAM status using anthropometric measurements. Once confirmed as MAM, children in the age group of 6-60 months without any chronic illness or major disease were included in the study after informed written consent from the parents. Post parental consent, the child was enrolled and assigned a unique ID. Children in the age group of 6 to 60 months were grouped into: A- 6 to 24 months and B- 25 to 60 months. The study protocol was approved by the Institutional Ethics Committee of LTM Medical College and LTMG Hospital and the trial was registered at ctri.nic.in as CTRI/2017/08/009260.

\section{Sample size calculation}

Sample size calculations carried out for a cluster RCT indicated minimum sample size of 101 for both, treatment, and control group. This enabled the detection of an effect of 1.5 SD for almost all test scores at $80 \%$ power and a type 1 error of $7.5 \%$. A total of 324 children were enrolled in the study of which, 186 children received MFF and 138 received government ICDS - THR (Figure 2).

Figure 2. Flow chart of the study methodology

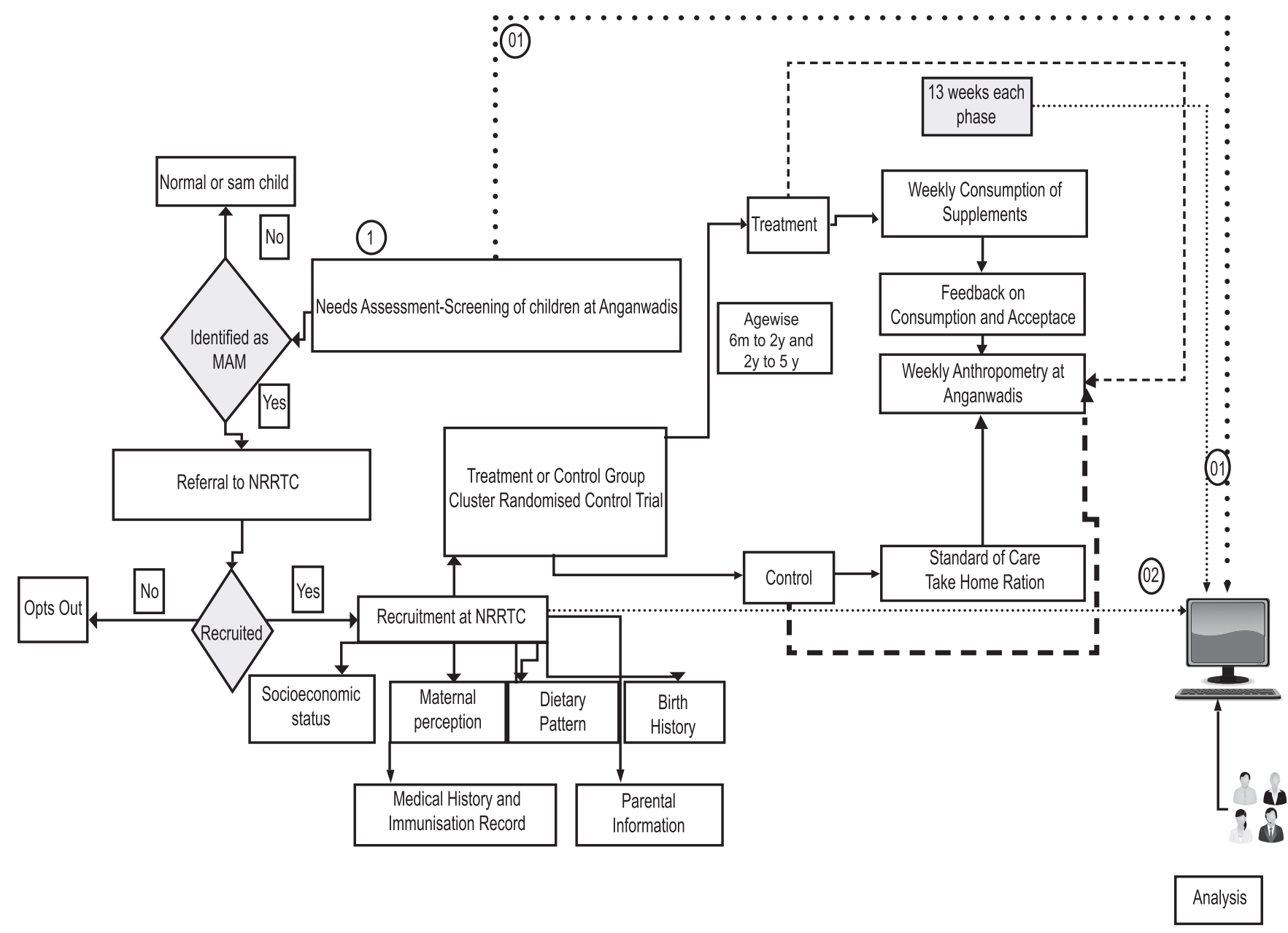




\section{Food Products and their distribution}

Children enrolled were subjected to de-worming by the paediatrician with albendazole $(200 \mathrm{mg}$ for children up to 24 months and $400 \mathrm{mg}$ for children above 24 months). Socio-demographic characteristics of children were recorded based on information collected from parents/guardians. Nutrition counselling and general healthy dietary and behavioural practices were reinforced amongst the parents. Caregivers were explained about benefits of supplementary feeding, along with instructions to continue providing the usual diet along with supplementary food and give it only to the enrolled child. In the $T$ group, the types of foods provided varied slightly based on the age-group. Children in 6-24 months age group received a 7-in-1 packet of MFF consisting of Upma Premix (UP), Ladoo Premix (LP), Ragi Porridge Premix (RP), Wheat Payasam Premix (WP), Kheer Premix (KP) and 2 packets of Ready to use Multi Grain Flour Paste (RUMF). All foods designed for them were semi-solid in consistency and each product provided $250-300 \mathrm{kCal}$ and $10-12 \mathrm{~g}$ proteins. The other group i.e. 25-60 months received a mix of semi-solid and finger foods providing 450$500 \mathrm{kCal}$ and $12-15 \mathrm{~g}$ proteins. The 7-in-1 packet for these children included UP, LP, Zunka Premix (ZP), Nankhatai (NK), Mathri (MT), Shakarpara (SK) and RUMF.

Food-products in premixes form were ready-to-cook, requiring a minimal cooking time of 5 minutes while products like Nankhatai, Mathri, Shakarpara and RUMF Paste were ready-to-eat. All MFF products were designed and developed by IIT-Bombay and its nutrient profile and shelf-life were analysed. The analysis for nutritive values was corroborated by a NABL accredited lab (TUV laboratories, Pune) (Appendix 1). Micronutrient powder for food fortification, designed for MAM children was supplied by Hexagon Nutrition Pvt Ltd, Nasik as per the specifications provided by IIT-Bombay. Children in control group received THR along with a measuring cup to consume the quantity as recommended by ICDS. Children in treatment group received a weekly supply of 7 -in-1 packet while those in control group were given a fortnightly supply of THR for a duration of 3 months.

\section{Nutrition Education to Caregivers}

Nutrition counseling was provided to all caregivers at enrolment and at regular intervals in the community by the community organizers and anganwadi workers. The key messages included: (i) Introduction of weaning foods to children at 6 month along with continuation of breast-feeding until child is 2 years old; (ii) Washing hands with soap and water before eating/ feeding and after using the toilet or cleaning the child; (iii) Encouraging healthy eating practices in the family; (iv) Boiling drinking water; (v) Inclusion of seasonal fruits and vegetables into child's diet; (vi) Encourage consumption of animal foods such as milk/milk products, fish, eggs and chicken where acceptable; (vii) Addition of pulses and nuts in every day meals of children; (viii) Storage of food and water hygienically; (ix) Avoid giving tea/coffee/junk food like chips and toast daily to the child.

\section{Measurements and Data Analysis}

Weight was measured with accuracy of $5 \mathrm{~g}$ using a portable electronic infant scale. Length was measured using an infantometer (for infants) and stadiometer (for elder children) to the nearest $2 \mathrm{~cm}$. MUAC was measured with a non-elastic tape standardized by UNICEF. Weight-for- height Z-score was calculated based on the WHO's 2006 Child Growth Standards and calculated for analysis using Emergency Nutrition Assessment for SMART 2011. ${ }^{15}$

\section{Statistical Analysis:}

Statistical analysis was carried out in Microsoft Excel and STATA (statistical software package) version 14 (College Station, Texas). Descriptive statistics were calculated for all variables including mean and standard deviation. The difference in means was calculated using student's t-test and 0.05 significance level.

Appendix 1. Nutritive value of the developed / treatment foods

\begin{tabular}{|c|c|c|c|c|c|}
\hline Products & $\begin{array}{l}\text { Moisture } \\
\text { (g) }\end{array}$ & $\begin{array}{c}\text { Carbohydrates } \\
\text { (g) }\end{array}$ & $\begin{array}{l}\text { Energy } \\
\text { (K Cal) }\end{array}$ & $\begin{array}{l}\text { Fat } \\
(\mathrm{g})\end{array}$ & $\begin{array}{l}\text { Protein } \\
\text { (g) }\end{array}$ \\
\hline Upma Premix (UP) & 1.6 & 50.6 & 519 & 28.2 & 15.6 \\
\hline Zunka Premix (ZP) & 2.2 & 34.5 & 531 & 33.1 & 23.8 \\
\hline Ladoo Premix (LP) & 1.8 & 53.1 & 522 & 15.8 & 27.7 \\
\hline Kheer Premix (KP) & 2.5 & 66.0 & 423 & 9.3 & 18.9 \\
\hline Wheat Payasam Premix (WP) & 1.6 & 49.3 & 513 & 27.6 & 16.9 \\
\hline Ragi Porridge Premix (RP) & 1.7 & 65.0 & 452 & 14.1 & 16.4 \\
\hline Nankhatai (NK) & 11.9 & 40.5 & 545 & 35.2 & 16.2 \\
\hline Ready to use multigrain flour paste (RUMF) & 1.5 & 40.2 & 565 & 36.4 & 19.1 \\
\hline Mathri (MT) & 4.1 & 41.7 & 512 & 29.2 & 20.6 \\
\hline Shakarpara (SK) & 3.5 & 37.9 & 521 & 30.0 & 24.7 \\
\hline
\end{tabular}




\section{Results}

The recruitment was carried out in three phases staggered over a month. Overall, 324 children were recruited in the project (186 in treatment and 138 in control group). Out of these, the children who did not come during anthropometry for more than 4 weeks continuously were excluded from the analysis and were considered as dropouts. Out of 324 , the data was analysed and presented for 248 children (140 in T group and 108 in C group). The baseline characteristics of the MAM children enrolled in the project is given in Table 1 . The weight and height of control group children was slightly higher than that of the treatment group children, which could be attributed to the greater number of older children (37-60 m) in $\mathrm{C}$ group compared to $\mathrm{T}$. The birth weight of recruited children was about $2.5 \mathrm{~kg}$ in both the arms of the study and $95 \%$ children were fed colostrum. A deficit in the number of months of breastfeeding was observed, as mothers reported feeding the children in the $\mathrm{T}$ group for $\sim 5$ months and those in the $C$ group for $\sim 4$ months $(p<0.04)$. Overall weight gain in T-group after 3 months of supplementation was $0.75 \pm 0.61 \mathrm{~g} / \mathrm{kg} / \mathrm{d}$ and in $C$ group was $0.52 \pm 0.79 \mathrm{~g} / \mathrm{kg} / \mathrm{d}(p=0.01)$. At the end of 6 months, the average weight gain was $0.57 \pm$ $0.36 \mathrm{~g} / \mathrm{kg} / \mathrm{d}$ and $0.44 \pm 0.45 \mathrm{~g} / \mathrm{kg} / \mathrm{d}$ for $\mathrm{T}$ and $\mathrm{C}$ group respectively $(p=0.01)$. The treatment foods had greater acceptability and correspondingly higher consumption (75-80\%) compared to that of THR (50-60\%).

The number of children in MAM using $\mathrm{WHZ}$ criterion reduced by $39.2 \%$ during the first 3 months of intervention period in T group and by $33 \%$ in $\mathrm{C}$ group. During follow up period, relapse into MAM was seen in $26(48.1 \%)$ children in T group, and $20(52.6 \%)$ children in $\mathrm{C}$ group. In figure 3 , it is seen that the $T$ group children have come out of MAM category with an average $z$ score of -1.9 compared to $C$ group children whose mean $z$ score $(-2.02)$ indicating MAM condition, after 3 months of intervention. This trend continued during the follow-up period. Mean $\mathrm{WHZ}$ between the enrolment (mean z-score -2.28) and treatment period (mean z-score -1.95) was significant

Table 1: Characteristics of children in the treatment and control group

\begin{tabular}{lccccc}
\hline & \multicolumn{2}{c}{ Treatment group } & \multicolumn{2}{c}{ Control group } & p value \\
\hline Variable & Mean & SD & Mean & SD & \\
\hline Age in months* & 29.76 & 14.85 & 35.93 & 14.78 & 0.001 \\
Male child & 0.46 & 0.50 & 0.46 & 0.50 & 0.98 \\
On admission & & & & \\
Kheer Premix (KP) & 2.5 & 66.0 & 423 & 9.3 & 18.9 \\
Weight (kg)* & 9.05 & 1.84 & 9.88 & 2.08 & 0.001 \\
Height (cm)* & 82.07 & 9.94 & 86.36 & 10.77 & 0.001 \\
MUAC (cm)* & 12.93 & 0.70 & 13.13 & 0.70 & 0.02 \\
Weight-for-height z-score (WHZ) & -2.29 & 0.44 & -2.26 & 0.39 & 0.61 \\
Height-for-age z-score (HAZ) & -2.23 & 1.14 & -2.20 & 1.13 & 0.86 \\
Weight-for-age z-score (WAZ) & -2.82 & 0.65 & -2.79 & 0.65 & 0.71 \\
Birth weight (kg) & 2.51 & 0.46 & 2.56 & 0.53 & 0.44 \\
6m-23m (Group A) & 2.55 & 0.36 & 2.45 & 0.64 & 0.33 \\
24m-59m (Group B) & 2.48 & 0.51 & 2.60 & 0.48 & 0.13 \\
At end of treatment & & & & & \\
WHZ & -1.92 & 0.66 & -2.01 & 0.68 & 0.09 \\
HAZ & -1.89 & 3.52 & -1.57 & 3.88 & 0.50 \\
WAZ & -2.47 & 1.79 & -2.40 & 1.93 & 0.88 \\
At end of follow-up & -2.01 & 3.12 & -1.77 & 3.56 & 0.59 \\
WHZ & 140 & 1.71 & -2.49 & 1.87 & 0.96 \\
HAZ & & & & & \\
WAZ & & & & & \\
Observations & & & & & \\
\hline
\end{tabular}

*indicates significant difference between two groups at 95\% confidence interval 
$(\mathrm{p}<0.05)$. However, when the $\mathrm{T}$ and $\mathrm{C}$ group clusters were compared using a two-sample t-test there was no significant difference between the two study arms in each of the three time-points taken separately $(p>0.05)$.

Figure 3. Shift in z-scores of children at the end of 3 months of supplementation and end of 6 months (follow up)

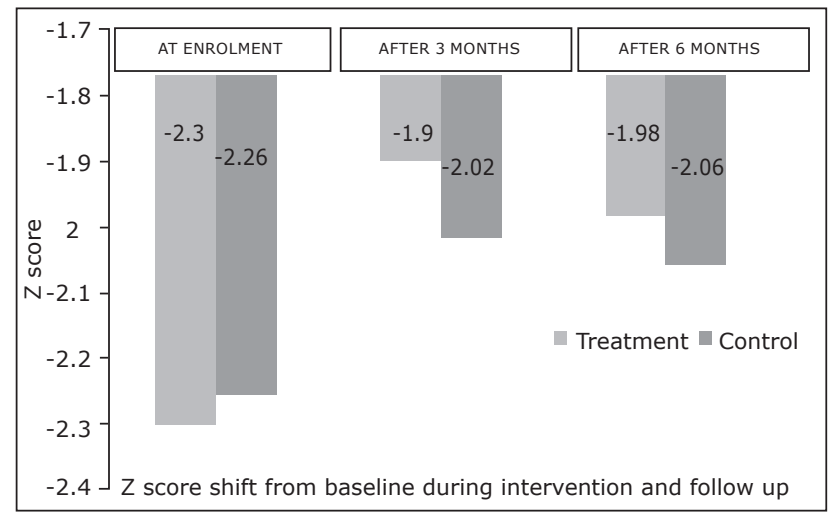

\section{Discussion}

Our results display considerable promise in the multisectoral approach towards community management of moderate acute malnutrition in children. The study results indicate a higher weight gain in children recruited in the treatment group, plausibly owing to the variety in the supplementation and palatability specific to the age categories. Another reason for the trend obtained could be due to the quantity of food consumed, which was consistently monitored by the anganwadi workers. Since the T group received a 7-in-1 Packet containing both categories of food, namely; RTC and RTE which was distributed to each recruited child, ensuring each child getting both categories of foods in equal measure. This may have also influenced the consumption thus directly impacting the weight gain.

High energy density of the treatment foods significantly reduces the bulk volume of the food compared to THR which is usually prepared as a porridge. Also, due to individual packaging, the treatment foods could have been interpreted as a therapeutic product ensuring the consumption by enrolled children compared to THR which is usually prone to sharing amongst family members. The provision of high-density energy foods to the treatment group could be a determinant of a higher rate of weight gain among $T$ group children. One reason for the trend obtained could be due to the amount of food consumed, which was monitored by the anganwadi workers. The treatment foods had greater acceptability and correspondingly higher consumption (75-80\%) compared to that of THR (50-60\%). While some of the treatment food was RTE, the RTC foods were easier to prepare and took less time compared to THR. This could have influenced the consumption thus directly impacting the weight gain.

\section{Conclusion}

The weight gain on an average was found to be higher in the $T$ group children who consumed the MFF compared to the $\mathrm{C}$ group children who consumed THR. Better results in weight gain could have been obtained if the intervention was for a longer duration. Since the high energy density food had low bulk volume, it may have been more acceptable and easily consumed by the children.

\section{Compliance with Ethical Standards}

Funding: This research was supported by the Tata Centre for Technology and design at IIT-Bombay.

\section{Conflict of Interest: None}

\section{References:}

1. World Bank. India, Undernourished children: A call for reform and action. [Last accessed on $2014 \mathrm{Apr}$ 05]. Available from: http://web.worldbank.org/ WBSITE/EXTERNAL/COUNTRIES/SOUTHASIAEXT/0, contentMDK:20916955 pagePK: $146736 \sim \mathrm{piP}-$ K:146830 theSitePK:223547,00.html.

2. Burtscher D, Burza S. Health-seeking behaviour and community perceptions of childhood undernutrition and a community management of acute malnutrition (CMAM) programme in rural Bihar, India: a qualitative study. Public health nutrition. 2015;18:3234-43.

3. Chang CY, Trehan I, Wang RJ, Thakwalakwa C, Maleta K, Deitchler M, Manary MJ. Children Successfully Treated for Moderate Acute Malnutrition Remain at Risk for Malnutrition and Death in the Subsequent Year after Recovery. J Nutr. 2013;143:215-20.

4. Ghosh S, Shah D. Nutritional problems in urban slum children. Indian Pediatr. 2004;41:682-96.

5. WHO child growth standards: methods and development. Geneva, World Health Organization, 2006. Available at URL: https://www.who.int/childgrowth/standards/technical_report/en/. Accessed on 5th Jan 2020

6. LaGrone LN, Trehan I, Meuli GJ, Wang RJ, Thakwalakwa C, Maleta K, Manary MJ. A novel fortified blended flour, corn-soy blend "plus-plus," is not inferior to lipid-based ready-to-use supplementary foods for the treatment of moderate acute malnutrition in Malawian children. Am J Clin Nutr. 2012 Jan;95(1):212-9.

7. De-Regil LM, Jeffers MED, Sylvetsky AC, Dowswell T. Intermittent iron supplementation for improving nutrition and development in children under 12 years of age. Cochrane Database Syst Rev 2011; 12: CD009085.

8. Allen LH, Peerson JM, Olney DK. Provision of multiple rather than two or fewer micronutrients more effectively improves growth and other outcomes in micronutrient-deficient children and adults. J Nutr 2009; 139: 1022-30.

9. Imdad A, Bhutta ZA. Effect of preventive zinc supplementation on linear growth in children under 5 years of age in developing countries: a meta-analysis of studies for input to the lives saved tool. BMC Public Health. 2011; 11 (suppl 3): S22.

10. Yakoob MY, Theodoratou E, Jabeen A, et al. Preventive zinc supplementation in developing countries: impact on mortality and morbidity due to diarrhoea, pneumonia and malaria. BMC Public Health 2011; 11 (suppl 3): S23.

11. Wood J, Sibanda-Mulder F Improvement of fortified blended foods CSB products and Unimix Available from: http://www.unicef.org/supply/files/8._Improvement_of_ Fortified_Blended_Foods_CSB_Products_and_Unimix. pdf (cited 8 August 2011). 
12. Matilsky DK, Maleta K, Castleman T, Manary MJ. Supplementary feeding with fortified spreads results in higher recovery rates than with a corn/soy blend in moderately wasted children. J Nutr. 2009;139:773-8.

13. Nackers F, Broillet F, Oumarou D, Djibo A, Gaboulaud V, Guerin PJ, et al. Effectiveness of ready-to-use therapeutic food compared to a corn/soy-blend-based pre-mix for the treatment of childhood moderate acute malnutrition in Niger. J Trop Pediatr. 2010;56:407-13.
14. Sazawal S, Dhingra U, Dhingra P, Hiremath G, Kumar J, Sarkar A, et al. Effects of fortified milk on morbidity in young children in north India: community based, randomised, double masked placebo-controlled trial. BMJ. 2007;334:140.

15. Assessment Emergency Nutrition. Software for standardized monitoring and assessment of relief and transitions (SMART), version 2011 